\title{
Toxoplasmosis y Embarazo
}

\author{
Dres.: Alberto Duarte-Contreras*, Clara Inés Duarte-Barreto** \\ y Gladys Duarte de Ruiz***
}

La toxoplasmosis se ha constituido en problema biológico y social y es por ello por lo que en los últimos años ha ocupado los primeros planos en la literatura médica. A partir de 1950, fecha en la que se hizo el primer diagnóstico de toxoplasmosis ganglionar en vida, han aparecido más de cincuenta mil publicaciones, cantidad apenas superada por la de investigaciones sobre el cáncer. Ello se debe a la amplia difusión universal del parásito, a su alta prevalencia en animales incluyendo al hombre, a que tanto su ciclo biológico como los mecanismos de transmisión sólo datan de 1970 y a que sus características biológicas, en especial su reproducción exclusivamente intracelular, han permitido que sea modelo en la investigación que se adelanta en el campo de la inmunología.

* Médico de la Consulta de Ginecología Infantil del Hospital San Juan de Dios, Cúcuta.

** Bacterióloga y Laboratorista Clínico de la Universidad Javeriana y Microbióloga de la Universidad de Los Andes.

*** Bacterióloga y Laboratorista Clínico de la Universidad Javeriana.
Cuando la toxoplasmosis se adquiere durante el embarazo no causa mayores molestias a la madre, en cambio puede afectar tan severamente al producto que le inhabilita para su comportamiento posterior en el desempeño productivo como persona, a más de los trastornos y problemas que implican su presencia dentro del conglomerado social y familiar (39). Maekel dice que en 1983 la toxoplasmosis congénita clínicamente manifiesta se presentó en Venezuela en 893 recién nacidos (28). Esta cifra constituye de por sí un hecho que debemos considerar grave $y$ que nos obliga a estudiar a fondo el problema de la Toxoplasmosis congénita. En Colombia la población parasitaria constituye el $47.1 \%(11)$.

$\mathrm{La}$ toxoplasmosis es una zoonosis producida por un esporozoario del grupo de los coccídeos, el Toxoplasma Gondii, descubierto desde principios del siglo. Es un parásito intracelular que se encuentra ampliamente difundido por el mundo; constituye una de las infecciones más extendidas $y$ no existe animal de sangre caliente que escape a sus efectos. Por múltiples encuestas serológicas se sabe que esta zoonosis parasita algo más del $40 \%$ de la humanidad (5) y su prevalencia varía según los diferentes grupos de edad, 
siendo más alta en los mayores de diez años (48).

Se la encuentra en todas las latitudes, tanto en la población humana como en más de trecientas especies de mamíferos domésticos y salvajes y cerca de treinta especies de aves de corral y silvestres (47).

El toxoplasma tiene la forma de una pera o de semiluna, de 6 a 9 micras de largo y de 1 a 4 de ancho. Es un parásito, gram negativo; no tiene órganos de movimiento ni cinetoplasto, por lo cual no es móvil. Sólo a temperatura de $37^{\circ} \mathrm{C}$ realiza movimientos ondulantes mínimos. No se puede cultivar en medios artificiales pero sí en tejidos de cultivo. Cumple su ciclo biológico en dos etapas: una fase asexuada que se lleva a cabo en un huésped intermediario, vertebrado y otra fase sexuada que se desarrolla en el huésped definitivo, el gato (31).

La fase asexuada se desarrolla en cualquier célula de mamíferos o aves excepto en los eritrocitos no nucleados y se comporta como un patógeno intracelular obligado. Esta fase es proliferativa primero y luego quística, con quistes latentes y parasitantes.

La segunda fase o sexuada está constituida por un ciclo gameto-esporogónico que se desarrolla en el epitelio del intestino de algunos felinos, especialmente del gato doméstico quien lo adquiere por sus costumbres carnívoras. Dentro de las células epiteliales de las vellosidades del intestino se forman los macro y microgametos. Los cigotes que resultan de la fecundación de los macrogametos generan los ooquistes que van a la luz intesti nal para eliminarse por las heces. Estos ooquistes mononucleares no son infectantes mientras no maduren ya en el exterior, a una temperatura de $27^{\circ} \mathrm{C}$., en dos o tres días sufren un proceso de esporulación que los convierte en infectantes.

Un gato infectado puede excretar varios millones de ooquistes en un día y con esta eliminación puede mantenerse de 7 a 15 días. Por lo general los gatos jóvenes menores de 6 meses, eliminan mayor cantidad de ooquistes que los gatos viejos. En climas fríos es más tardía la esporulación. A temperaturas de $11^{\circ} \mathrm{C}$ la maduración demora 25 días; a $4^{\circ} \mathrm{C}$, se detiene el desarrollo. Cuando las condiciones de calor y de humedad son favorables, pueden permanecer infectantes hasta por más de un año. Son destruidos por congelación, por calentamiento superior a los $55^{\circ} \mathrm{C}$ y por deshidratación.

Estos ooquistes pueden ser ingeridos de manera directa o indirecta por una gran cantidad de huéspedes o pueden ser transportados por infinidad de invertebrados coprófagos como la cucaracha y la mosca.

El gato generalmente tapa sus deyecciones, pero dada la baja densidad de los ooquistes y la humedad de la tierra afloran y se ponen fácilmente en contacto con vectores mecánicos como invertebrados coprófagos o con la mano del hombre.

Cuando los gatos defecan sobre suelo duro (baldosa, ladrillo, cemento), los ooquistes, por su bajo peso pueden flotar en el aire $y$ entonces el hombre los ingiere por inhalación. Wallace ha demostrado que en atolones del Pacífico carentes de felinos, no se encuentra la infección toxoplásmica (44).

La infección ataca con mayor severidad a los dos extremos de la vida: los embriones, los fetos y los ancianos, por 
haber en ellos un déficit de defensa inmunológica (38).

A pesar de haber un elevado porcentaje de infección, es muy baja la morbimortalidad. Esto significa que en la mayoría de los casos la toxoplasmosis pasa inadvertida, es asintomática (7). A veces se observa la sintomática.

La asintomática o subclínica puede presentar diversas manifestaciones muy leves, como discreto malestar general, estado catarral, mialgias, micropoliadenia de predominio cervical, episodios muy parecidos a los que se observan en la mononucleosis infecciosa. Se cree que el 13\% de las adenopatías de causa desconocida son producidas por toxoplasmosis adquirida.

La sintomática se observa en pocas oportunidades. Su sintomatología es espectacular y difiere según el órgano o el sistema afectado; puede haber cuadros de toxoplasmosis generalizada; las formas exantemáticas o seudotíficas son poco frecuentes, lo mismo que las ganglionares. Más raras aún son la miocarditis, la neumonitis, la hepatitis, la retinocoroiditis y excepcional el síndrome meningoencefálico, convulsivo, con compromiso del sisten a nervioso central, casi siempre mortal $(6,14,48)$.

Werner para dar una idea de la toxoplasmosis en la clínica humana suministra los siguientes datos: el $20.5 \%$ de los retardos mentales se deben al parásito, 7\% de las cegueras no traumáticas" se deben a toxoplasmosis congénita, del 15 al $25 \%$ de todas las uveítis son congénitas y producidas por el toxoplasma Gondii.

Desde el punto vista clínico podemos considerar la toxoplasmosis como 1 adquirida, 2 - congénita.

\section{TOXOPLASMOSIS ADQUIRIDA}

La toxoplasmosis adquirida se puede iniciar en cualquier momento a partir del nacimiento y su comienzo pasa desapercibido; habitualmente ocurre a través del aparato digestivo.

La persona adquiere la infección cuando después de haber entrado en contacto directo con tierra contaminada (los niños en sus juegos y los adultos en la horticultura) lleva las manos sucias a la boca o toma alimentos sin practicar un lavado previo, o al comer carnes crudas o insuficientemente cocidas (quipe crudo, hamburguesas, bistek un cuarto de asado). La carne cruda guardada en refrigerador a menos de $4{ }^{\circ} \mathrm{C}$ mantiene su capacidad infectante hasta por cuatro semanas; a menos $15^{\circ} \mathrm{C}$ los quistes se destruyen en tres días. La cocción destruye los quistes. Cuando una carne en cecina contiene quistes o se le trata con salmuera o ahumados, pierde su poder infectante.

Las transfusiones constituyen otra fuente de contagio. En los bancos de sangre el toxoplasma se mantiene viable en los leucocitos hasta por 50 días a menos de $4^{\circ} \mathrm{C}$. Esta fuente de infección reviste suma gravedad en los inmunosuprimidos, por ejemplo en los pacientes con leucemia, tan necesitados de sangre transfundida; por ello se debe tener sumo cuidado en no suministrar sangre de donantes con toxoplasmosis aguda a pacientes embarazadas o inmunológicamente suprimidos. Para ser donante de sangre se requieren personas aparentemente sanas. Aun cuando alrededor del $60 \%$ de los donantes se encuentran portadores de anticuerpos, antitoxoplasma, no se les relega como personas no aptas para una donación pues ellos en realidad son portadores de defensas. 
El transplante de órganos es otra de las fuentes de contagio. Existe la infección accidental a personal que trabaja en laboratorios o a quienes manipulan o preparan carnes cuando éstas están infectadas $(32,33)$; se adquieren entonces a través de cualquier solución de continuidad en las manos: los taquizoítos se ponen de inmediato en contacto con los tejidos $y$ en seis segundos ya han traspasado la membrana celular y penetrado al sistema circulatorio.

Se ha demostrado experimentalmente que animales como vacas y cerdos con infección aguda, eliminan parásitos por la leche; pero no se ha encontrado transmisión de toxoplasma a través de la leche materna.

Excepcionalmente se han hallado toxoplasmas en huevos de gallina (23). También se han observado trofozoítos en el exudado alveolar, saliva y lágrimas de animales de experimentación y en seres humanos pero en cantidades tan reducidas que no parecen ser fuente de infección con importancia epidemiológica. Así la toxoplasmosis deja de ser la tan temida enfermedad del beso.

Pueden existir otros vectores $y$ otros mecanismos de infección humana desconocidos hasta ahora.

La patogenicidad depende de la virulencia de la cepa y del estado inmunitario del huésped. Los estudios de Matsubayashi y Akao en cultivos de tejidos y en an males de experimentación permiten deducir que los toxoplasmas virulentos producen las infecciones agudas más intensas, dando lugar a una mayor respuesta inmunitaria (30). El feto en desarrollo y la persona comprometida en su sistema inmunitario son los más vulnerables a la expresión patológica de la infección masiva que causa enquistamiento en el ojo o en el cerebro.

\section{EVOLUCION}

En la evolución de la toxoplasmosis se consideran tres etapas:

\section{La INVASION o CONTAMINACION}

se hace generalmente al ingerir por vía oral las formas quísticas. Se liberan los toxoplasmas, se multiplican las formas libres y penetran en las células, al tiempo que la infección se generaliza en el organismo. Los endozoítos liberados de las células huéspedes destruidas circulan libremente por vía linfática y sanguínea.

Por lo general los macrófagos los transportan à otros órganos y van a refugiarse en las células del sistema retículo endotelial: en este instante puede presentarse un cuadro clínico severo, la toxoplasmosis generalizada, que llega a ocasionar en la mujer embarazada una fetopatía grave y aún mortal.

\section{FORMACION DE ANTICUERPOS.}

Durante el período de invasión parasitaria se incrementa la estimulación antigénica y se aprecia un aumento progresivo y rápido de los mecanismos inmunitarios. Con ello empiezan a escasear las formas libres, menos en el ojo y en el cerebro, órganos carentes de anticuerpos ya que no poseen elementos linfoides $(41,46)$. Dos o tres semanas después de iniciada la infección parasitaria se pueden detectar mecanismos inmunitarios específicos (anticuerpos antitoxoplasma IgG e $\lg M)$.

La infección toxoplásmica da como resultado la producción de anticuerpos 
$\lg$ e IgM. Los anticuerpos son sintetizados por las células linfoides.

Se ha demostrado que cuando los trofozoítos infectantes entran en contacto con los anticuerpos, aumenta la capacidad de los macrófagos para destruirlos y parece que por este mecanismo se reduce el número de parásitos del huésped infectado. El parásito puede multiplicarse hasta cierto límite dentro de los macrófagos antes de que sean destruidas las células del huésped y cuando ésto ocurre los trofozoítos extracelulares entran en contacto con los anticuerpos y pueden ser destruidos más fácilmente por los macrófagos. También se produce interferon y se ha demostrado que los macrófagos activados matan al parásito o inhiben su actividad. Todo ésto da a entender que se requiere un sistema inmunológico intacto para la protección contra el toxoplasma. El toxoplasma puede alterar los macrófagos, hecho que hace deficiente la información inmune y como respuesta se presenta una deficiencia inmunológica celular.

La mayor parte de las personas adquieren protección adecuada después de la infección natural (19).

Los títulos de IgG van aumentando de manera gradual, para estabilizarse en seis a ocho semanas a niveles iguales o superiores a 1:1024 y permanecer a títulos iguales o superiores por seis meses aproximadamente; luego descienden pero no llegan a desaparecer completamente y permanecen de por vida a títulos aproximados a 1:32. Según la virulencia de la cepa infectante será mayor o menor la cantidad de anticuerpos IgG que se puedan producir, observándose en algunos casos cifras iguales y aún superiores a 1:16.384 (35).

Los anticuerpos IgM, que son específicos, aparecen primero y ascienden con mayor rapidez que los IgG, pero en cambio sus títulos casi nunca son superiores a $1: 64$; persisten en promedio por cuatro meses e inician su descenso para desaparecer totalmente entre pocas semanas $y$ un año.

Una vez constituida la respuesta inmune celular o humoral solamente logran sobrevivir los toxoplasmas enquistados. Para que se efectúe la síntesis de los anticuerpos es indispensable un sistema inmunológico intacto, sin inmunosupresión; por esta razón se explica por qué en los extremos de la vida, el feto en desarrollo $y$ el anciano, o en el huésped comprometido en su sistema inmunitario sea tan notoria la vulnerabilidad a la expresión patológica de la infección masiva que causa enquistamiento en el ojo y en el cerebro.

3. En una tercera etapa o ETAPA CRONICA los parásitos prefieren albergarse en las células de tejido muscular o nervioso, donde persisten y se protegen por la formación de quistes. El toxoplasma permanece indefinidamente en los tejidos pero no es agresivo debido a la inmunidad celular; se ha formado un equilibrio entre parásito y huésped. Está demostrado que todos los tejidos orgánicos, incluyendo los del aparato genital femenino, con excepción del folículo y del epitelio cilíndrico de las trompas son susceptibles de la infección toxoplásmica y por lo tanto se pueden encontrar en ellos las formas quísticas

\section{TOXOPLASMOSIS CONGENITA}

La transmisión congénita se realiza por vía transplacentaria, siendo la madre el factor directo; constituye el aspecto más importante de la infección humana. 
Para que una infección toxoplásmica se pueda considerar como congénita es indispensable que la madre haya adquirido el contagio durante el embarazo que cursa. Si la toxoplasmosis ha sido adquirida antes del embarazo en curso, ni el producto actual ni los productos futuros corren el riesgo de adquirir in útero la infección toxoplásmica, o sea no nacerán con toxoplasmosis congénita.

Hunter dice que la incidencia global de toxoplasmosis congénita se calcula actualmente en un caso por ocho mil quinientos nacimientos (22). En nuestro medio se considera que se encuentra entre el 0.5 y el 5 por mil nacidos vivos (40), y de éstos el $75 \%$ no presentan síntomas en el período post-natal pero pueden desarrollar más tarde secuelas desfavorables de la infección.

Cuando la toxoplasmosis se adquiere durante el embarazo, éste puede terminar en aborto, o en parto prematuro o a término, con recién nacido vivo, infectado o no, o con mortinato, según la agresividad del toxoplasma, la respuesta inmunológica y sobre todo la edad de la gestación en que se ha adquirido la infección.

Casi todos los productos que se infectan durante los dos primeros meses terminan en muerte del embrión. La infección de la madre durante el segundo trimestre puede producir hidrocefalia, ceguera o un grado variable de lesiones neurológicas menores. En la mayoría de los casos de toxoplasmosis en recién nacido, la infección se ha verificado durante el primer trimestre.

No toda gestante que se infecta enferma al producto. Así, de las madres que se infectan durante un embarazo, solamente el $50 \%$ de los recién nacidos nacen infectados, enfermos o no, y de ellos el 83\% han adquirido la infección toxoplásmica pero no nacen enfermos sino sanos, sin secuelas; sólo el $17 \%$ nacen enfermos con trombocitopenia, hepatoesplenomegalia o la triada de Sabin (coriorretinitis, calcificaciones difusas intracraneales e hidrocefalia) $(12,34,39)$, y de este $17 \%$ de recién nacidos con toxoplasmosis congénita clínicamente manifiesta, $46 \%$ muestran daños leves, $28 \%$ muestran daños graves $y 26 \%$ son mortinatos.

Como en los dos primeros meses apenas se está organizando el sistema nervioso central, el daño que padece el producto es grande $y$ por ello muchos de estos embriones mueren $y$ son abortados ya que al principio de la gestación, en la mayoría de las especies animales es muy escasa o nula la elaboración de anticuerpos, posiblemente por inmadurez inmunológica o porque la exposición a antígenos extraños se ve limitada por la barrera de las membranas que le revisten (19). Puede deberse también a la acción directa del parásito o a trastornos nutritivos que impiden el desarrollo normal del embrión. Esto explica por qué la infección congénita sea tan escasa en los recién nacidos de este grupo. El reducido número de embriones que sobreviven nacerán con coriorretinitis, microoftalmía y otros defectos oculares, reducción de la capacidad de aprendizaje, retardo mental y otras manifestaciones de deficiencia del sistema nervioso central, o con una lesión latente asintomática que puede hacerse patente años después (27). Este fenómeno se explica por la eliminación de los linfocitos sensibilizados previamente, limitando una infección inaparente o por incapacidad del huésped con inmunosupresión para montar una respuesta protectora adecuada a una nueva infección. 
Es posible la reactivación de la toxoplasmosis durante un embarazo pero hasta la fecha no se ha confirmado ni descrito el primer caso de toxoplasmosis congénita por reactivación.

Es probable que la infección sea transmitida al feto únicamente si la madre presenta parasitemía antes de tener anticuerpos circulantes (7).

Cuando el feto se enfrenta a estimulación antigénica potente, los primeros y principales anticuerpos que se forman son los del tipo IgM.

Los anticuerpos IgM no atraviesan la placenta humana, en cambio los IgG la atraviesan libremente a partir del tercer mes de gestación. El transporte activo y selectivo de lgG a partir del tercer mes de vida intrauterina produce concentración sérica mayor de esta inmunoglobulina en el feto que en la madre. El transporte de IgG de la madre al feto excede del que ocurre en sentido opuesto. Estos anticuerpos adquiridos pasivamente durante la vida fetal defienden al neonato durante las primeras semánas antes de que adquiera capacidad para elaborar anticuerpos protectores. Los anticuerpos producidos por el feto en el caso de infección toxoplásmica son del tipo IgM (46).

Se tienen pocos datos acerca de la formación de anticuerpos IgG por el feto (46). Después de la semana veinte de gestación, el feto puede producir respuesta de anticuerpos cuando se-somete a estímulos intensos; se desconoce el grado en el cual una reacción de este tipo pueda aumentar la protección brindada por los anticuerpos IgG maternos.

La escasa elaboración de anticuerpos en el feto obedece a: 1 - inmadurez in- munológica, 2 - a que la exposición a antígenos extraños se ve limitada por la barrera de las membranas que revisten al feto. Cuando el embrión o el feto se enfrentan a un estímulo antigénico potente, como el toxoplasma, se forman de inmediato anticuerpos del tipo IgM, considerados como específicos de la toxoplasmosis pero son insuficientes para protegerlo de la presencia de altas concentraciones de toxoplasma: se les encuentra en baja concentración en el cordón umbilical. Cuando hay altas concentraciones de IgG y de IgM en el cordón umbilical es signo de infección toxoplásmica reciente.

\section{DIAGNOSTICO}

Bien conocidas son las dificultades que existen para el diagnóstico del toxoplasma en los tejidos de las pacientes con manifestaciones clínicas de la enfermedad. En cambio, el diagnóstico se hace con relativa facilidad investigando la presencia de anticuerpos específicos sea por medio de la prueba cutánea de Frenkel o por métodos serológicos. Las pruebas que más se emplean son:

1. Intradermo reacción, ID, o prueba cutánea de Frenkel. Es una prueba cualitativa, útil cuando se trata de verificar inmunidad toxoplásmica fuera del embarazo. Se positiviza tardíamente seis a ocho meses después de iniciada la infección. No hay equivalencia entre la intensidad de la reacción y los títulos de anticuerpos revelados por el IFI. Su lectura se hace siete días después de aplicada la toxoplasmina, reactivo del tipo de la tuberculina que se inyecta por vía sub. cutánea y se interpreta de igual manera. Cuando da positividad, ésta se mantiene, al parecer, por toda la vida, de manera 
que cuando se encuentra reactiva durante la adolescencia queda excluido todo reconocimiento posterior. No se le da importancia clínica como método de diagnóstico pero es un gran recurso para encuestas epidemiológicas (1).

\section{La prueba de Sabin Feldman, o Dye}

Test, o prueba del colorante se ha empleado desde 1948. Es una prueba de lisis de los toxoplasmas o de neutralización in vitro, o de exclusión del colorante azul de metileno. Se basa en la capacidad que tienen los anticuerpos para reaccionar ante el toxoplasma sobre el cual ejercen un efecto citotóxico en presencia de factores séricos normales. Como resultado se altera la pared del parásito no siendo posible teñirla con el azul de metileno.

El azul de metileno tiñe con facilidad los toxoplasmas, pero cuando se encuentran afectados por los anticuerpos adicionados con sueros frescos de un humano normal, no toman la coloración del azul de metileno. La lectura se reduce a establecer la relación existente entre los toxoplasmas teñidos y los no teñidos, tomando como base la cantidad de veinte toxoplasmas. Tiene dificultades técnicas; por requerir toxoplasmas vivos, fácilmente se infectan quienes la realizan. Es una prueba de alta sensibilidad y especificidad, que detecta anticuerpos desde ocho a diez días de iniciada la infección. Los títulos se elevan rápidamente, decrecen después de ocho a doce meses y quedan positivos, al parecer, de por vida. Se pueden encontrar títulos muy altos pero no hay paralelismo entre la gravedad de la enfermedad y el título. Ha dejado de ser una prueba de rutina, pero sigue siendo una prueba patrón con la cual se comparan las demás reacciones serológicas para toxoplasmosis (40). La respuesta se da en. U.I.
3. Hemoaglutinación indirecta, RHI, Se fundamenta en el hecho de que al tratar previamente hematíes con una solución de ácido tánico, sirven como portadores de un antígeno proteico hidrosoluble de toxoplasmas. Si estos hematíes sensibilizados se ponen en contacto con el suero de una persona que tenga anticuerpos específicos antitoxoplasma, estos glóbulos rojos se aglutinan específicamente. Es una prueba muy sensible que se positiviza catorce días después de iniciada la infección. Alcanza títulos tan altos como 1: 16.384 en la fase aguda, títulos que persisten por largo tiempo. La determinación cuantitativa no permite sacar conclusiones acerca de la positividad del proceso y así se pueden encontrar títulos muy altos en porsonas aparentemente sanas y títulos muy bajos, v.g. 1:64, en procesos inflamatorios destructivos localizados. Dada su gran sensibilidad, el requerimiento de volúmenes mínimos de suero, sin necesidad de microscopio ni de equipos costosos, es una reacción recomendada y empleada en muchos laboratorios (29).

\section{Aglutinación directa, AD. Es una} prueba similar a la de aglutinación indirecta pero con la diferencia de que en la directa se pone en contacto el suero sospechoso con una suspensión de toxoplasmas formalizados. Tiene la ventaja de no depender de parásitos vivos. Se lee directamente en el tubo de ensayo. Es una prueba muy simple y muy rápida que aglutina los anticuerpos antitoxoplasma IgG e IgM (16).

5. La prueba de Fijación del Complemento es muy específica pero es muy sensible. El resultado depende del extracto antigénico utilizado. Con antígenos 
de membrana o pesados, la cinética de los anticuerpos en la desviación del complemento es similar a la de los anticuerpos líticos. Al usar antígenos citoplásmicos o ligeros, la reacción se positiviza más tardíamente y se negativiza más rápidamente que en la prueba de Sabin (16). El antígeno se puede producir sin necesidad de manipular con cepas de toxoplasma.

\section{La prueba de Inhibición de la Hema-} glutinación es un método particularmente sensible y puede servir para el descubrimiento de los anticuerpos de la cámara anterior del ojo (3).

7. La reacción de aglutinación de partículas inertes, LATEX, depende del extracto antigénico utilizado para "sensibilizar" las partículas empleadas. La más usada es el TOXOTEST-MT (TMT). Es una prueba recomendada para rastreo (24).

\section{La Inmuno Fluorescencia indirecta,} IFI es el método más usado en la actualidad $(15,26)$. Es una prueba más simple que la de lisis. Se hace actuar sucesivamente sobre la extensión fijada de toxoplasmas el suero sospechoso más un conjugado fluorescente de antiglobulinas gama humanas en el que se ha verificado la ausencia de anticuerpos antitoxoplasma. Si el suero que se investiga es positivo los toxoplasmas se ven fluorescentes a la luz ultravioleta. Los resultados se expresan por dilución (16).

9. La prueba de Remington o IgM-IFI, es una reacción de inmunofluorescencia indirecta que utiliza un conjugado fluorescente anti IgM humano y pone de manifiesto los anticuerpos antitoxoplásmicos de tipo lgM formados durante la infección aguda tanto en la madre como en el feto. Como los anticuerpos IgM son de aparición precoz y desaparecen habitualmente en cuatro meses, la prueba no es positiva más que en la toxoplasmosis reciente. Es sencilla de ejecutar y valiosa para el diagnóstico temprano. Sin embargo, no dejan de presentarse algunos contratiempos que falsean la respuesta. Así, el feto aunque infectado puede no formar in útero anticuerpos $\operatorname{lgM}$; títulos altos de anticuerpos maternos IgG por competencia de sitios antigénicos pueden inhibir la demostración de anticuerpos específicos IgM; el factor reumatoideo y los anticuerpos antinucleares pueden dar falsos positivos $(2,16)$.

\section{El Inmuno Ensayo Enzimático o}

ELISA o EIA, es un método significativamente más específico y sensible para detectar anticuerpos antitoxoplasma IgM que la prueba IgM-IFI. Se basa en la captura de anticuerpos humanos IgM por un conjugado enzimático an tiglobulínico. Con este método se evita la interferencia causada en ocasiones por los anticucrpos lgG. Tampoco se observan los falsos positivos cuando en el suero que se investiga hay factor reumatoideo o anticuerpos antinucleares.

Es una prueba de excelentes resultados en el diagnóstico de la toxoplasmosis congénita $(2,24)$. Es una prueba de mayor sensibilidad que la IgM-IFI. Con ella se han logrado detectar cantidades muy bajas de IgM hasta doce meses después de iniciada la infección. Con miras al aumento de la sensibilidad de la prueba, se han ideado varios que emplean, por ejemplo, componentes polisacáridos del toxoplasma gondii, o anticuerpos anti IgM (Prueba Inmunoenzimática Reserva o de Captura) que dan títulos seis a 
treinta veces más al tos que la prueba IgMELISA clásica (10). El resultado se da en U.I.

11. La Inmuno Aglutinación Absorbente o Ensayo IgM Inmuno Absorbente, o IgM-ISA, elimina el uso del conjugado enzimático de la prueba ELISA y emplea la captura de preparaciones de antígenos particulados combinando rasgos de la prueba IFI con algunos de IgM-ELISA. Es más simple, más rápida, más sensible que la IFI-ELISA (4). Ni el factor reu. matoideo ni los anticuerpos antinucleares causan falsos positivos. Es una prueba específica. Si en lugar de las grandes cantidades de taquizoítos que requiere, se emplean partículas de Látex no requiere equipo especial para la lectura, la que se puede hacer a las tres horas y le permite adaptarse para su uso en el consultorio médico $(2,39)$.

12. Otros. Recientemente se ha incorporado el sistema biotina/avidina a las técnicas ELISA. Parece que este sistema aumenta significativamente la sensibilidad de las reacciones antígeno anticuerpo. Los sistemas de biotina/avidina se han empleado para acrecentar la tinsión inmunocitoquímica e inmunofluorescente (2).

A toda mujer embarazada se le debe ordenar en la primera consulta prenatal la investigación de anticuerpos antitoxoplasma tipo IgG, salvo a las que con anterioridad hayan presentado títulos positivos.

Si el examen revela anticuerpos IgG reactivos a cualquier título, es indispensable investigar si la infección es latente o es activa (reciente, tal vez con manifestaciones clínicas).

Se sabe que una prueba serológica reactiva indica solamente que ha habido infección, reciente o antigua, pero no que haya enfermedad evolutiva. Sólo un aumento progresivo y rápido del título de anticuerpos indica infección aguda.

Si los anticuerpos IgG son reactivos hay dos conductas por seguir: 1 - repetir el examen serológico tres semanas más tarde, 2 - investigar de inmediato, si es factible, la presencia de anticuerpos antitoxoplasma IgM.

\section{INTERPRETACION DEL IF I}

Si los anticuerpos antitoxoplasma IgG son reactivos en el primer examen, y tres semanas después han aumentado en tres diluciones o más, la toxoplasmosis de esta gestante es recientemente adquirida y se debe tratar de inmediato.

Si los anticuerpos antitoxoplasma IgG son reactivos y los anticuerpos antitoxoplasma IgM practicados de inmediato son también reactivos a cualquier dilución, la infección fue adquirida cuatro a ocho semanas antes de obtenido el suero: es una infección reciente y la paciente se debe tratar.

Si los anticuerpos antitoxoplasma IgG encontrados en los dos primeros meses del embarazo son iguales o mayores a 1 : 1024 pero estables, el feto no está en riesgo y por lo tanto no se debe iniciar tratamiento ya que los títulos altos encontrados no indican infección reciente: son anticuerpos circulantes y las defensas no se tratan, se estimulan.

Si en el primer o a principios del segundo trimestre los anticuerpos antitoxoplasma IgG, iguales o mayores a 1: 1024 permanecen estables a las tres semanas, o los anticuerpos antitoxoplasma 
IgM practicados de inmediato son negativos, la infección fue adquirida antes del embarazo. No requiere tratamiento.

Si al final del segundo o en el tercer trimestre los títulos IgG son iguales o mayores a 1: 1024 con aumento poco significativo en titulaciones posteriores, o con IgM negativo, es imposible saber si la infección se inició antes o después de la concepción (41). Lo importante en este caso es definir el tratamiento; somos partidarios de que se debe tratar a esta paciente (18).

El diagnóstico de toxoplasmosis aguda en un recién nacido, especialmente en las infecciones clínicamente inaparentés, es difícil y en algunos casos, no obstante las manifestaciones clínicas exuberantes, no siempre la sospecha clínica puede comprobarse a través de las pruebas serológicas $(9,20)$.

Como criterios para el tratamiento del recién nacido se toman: hallazgos de títulos altos de lgG mayores de 1:256, o títulos de IgG ascendentes, o positividad de IgM a cualquier dilución, o cuando la madre al final del embarazo tuvo títulos constantes de IgG iguales o superiores a $1: 1024$.

Para la interpretación de los hallazgos en la investigación de anticuerpos antitoxoplasma IgG por el método IFI, es prudente seguir las normas expresadas por el Centro de Control de Enfermedades CDS. Ellas son:

\section{1 - Títulos de 1:16 a 1:64}

Más del $30 \%$ de la población aparentemente sana se encuentra dentro de esta categoría. Indican una exposición anterior: hay una toxoplasmosis latente o crónica; o una infección reciente con iniciación en el aumento de los títulos.

\section{2 - Títulos de 1:256}

Más del $10 \%$ de la población aparentemente sana se ubica dentro de esta categoría. Indica que hay una exposición un poco menos reciente $y$ tal vez infección en desarrollo. Es un indicio para alertar al médico.

\section{3 - Títulos de 1:1024 o más}

Es un título indicativo de infección aguda, pero un solo examen no hace el diagnóstico; un aumento significativo en el título en un segundo examen da seguridad diagnóstica.

Todo ésto significa que pacientes embarazadas con títulos estables de 1:1024 o con IgM negativos, no se tratan Si tres semanas más tarde suben dos o tres veces los títulos IgG, se deben tratar.

En el caso de que con títulos altos de IgG, el IgM sea negativo, se debe permanecer alerta y controlar cada tres semanas el IgG para observar si se presenta ascenso o descénso, ya que los títulos elevados de IgG han podido bloquear la respuesta de los IgM (21).

Es indispensable conocer la equivalencia entre los títulos de anticuerpos antitoxoplasma IgG según se hayan investigado por los métodos ELISA o IFI.

\begin{tabular}{|r|c|c|}
\hline \multicolumn{2}{|c|}{ ELISA } & \multicolumn{1}{c|}{ IFI } \\
\hline \multicolumn{2}{|c|}{ menos 30 U.I. } & no reactiva \\
30 a 80 U.I. & $1: 64$ a $1: 128$ \\
100 a 200 U.I. & $1: 256$ a $1: 512$ \\
& 250 U.I. & $1: 1024$ \\
más de & 300 U.I. & mayor de $1: 1024$ \\
\hline
\end{tabular}


La relación entre anticuerpos antitoxoplásmicos e infección congénita se puede sintetizar en el siguiente cuadro:

\begin{tabular}{|l|l|l|}
\hline \multicolumn{1}{|c|}{ Ac tipo IgG } & Ac. tipo IgM & \multicolumn{1}{|c|}{$\begin{array}{c}\text { Infección } \\
\text { Congénita }\end{array}$} \\
\hline $1: 1024$ a $1: 2048$ & positivo & frecuente \\
$1: 1024$ a $1: 2048$ & negativo & rara vez presente \\
$1: 2048$ a $1: 4096$ o más & negativo & relativamente frecuente \\
menor de $1: 1024$ & positivo & posible \\
menor de $1: 1024$ & negativo & excluida \\
\hline
\end{tabular}

\section{TRATAMIENTO}

La mujer embarazada se trata solamente:

1 - cuando se demuestra que ha sido infectada durante la gestacion que cursa.

2 - cuando presenta una infeccion ocular activa toxoplásmica.

La retinocoroiditis toxoplásmica se debe sospechar en presencia de lesiones activas típicas y serología positiva a cualquier título, y en este caso la eficacia del tratamiento no se define serológicamente sino por la clínica.

Se debe tener presente que el propósito del tratamiento es la protección del feto sin producir efectos teratógenos.

Cuando existen títulos de anticuerpos estables, aun cuando éstos sean bajos, la inmunidad materna es generalmente suficiente para prevenir la infección fetal (18).

El tratamiento quimioterapéutico clásico con Pirimetamina más Sulfadiazina no se debe aplicar a la mujer embarazada ya que estas drogas pueden producir efec- tos teratógenos semejantes a los ocasionados con el methotrexate (36).

En la gestante las drogas de elección son la Spiramicina y la Clindamicina. La Spiramicina se concentra en la placenta pero no pasa al feto; se administra a razón de $500 \mathrm{mg}$. cada seis horas por tres semanas; el tratamiento se puede repetir con intervalos de quince días. Nosotros la suministramos dos o tres veces según el título de anticuerpos. La Spiramicina reduce la transmisión al feto, pero no aminora la severidad de la infección transmitida (13).

La Clindamicina es eficaz contra el trofozoíto y la forma quística; no es teratógena. Se la administra a razón de $300^{\prime} \mathrm{mg}$. cada seis horas hasta por tres semanas y se puede repetir varias veces con intervalos de quince días.

Cuando la infección se ha iniciado con títulos muy altos de anticuerpos, Frenkel recomienda el uso de sulfadiazina y pirimetamina más ácido folínico y levadura de cerveza, según el esquema clásico que indicamos en el siguiente cuadro: (18).

\section{QUIMIOTERAPIA DE LA TOXOPLASMOSIS EN EL ADULTO}

\begin{tabular}{|lcc|}
\hline Droga & $\begin{array}{l}\text { los tres } \\
\text { primeros días }\end{array}$ & $\begin{array}{l}\text { del cuarto día en } \\
\text { adelante por dos } \\
\text { semanas }\end{array}$ \\
\hline $\begin{array}{c}\text { Quimioterapia } \\
\text { Pirimetamina }\end{array}$ & $75 \mathrm{mg}$. & $25 \mathrm{mg}$. \\
Sulfadiazina & $500 \mathrm{mg}$. & $500 \mathrm{mg}$. \\
ANTAGONISTAS & & 2 a $10 \mathrm{mg}$. \\
Acido folínico & 5 a $10 \mathrm{~g}$. \\
\hline Levadura de cerveza & & \\
\hline
\end{tabular}

Nosotros, con gran temor, usamos este esquema en una paciente con resultado satisfactorio; pero, repetimos, con gran temor y preferimos no hacerlo. 


\section{PROFILAXIS}

La profilaxis en la embarazada tiene por mira la protección del feto. Toda mujer embarazada sin títulos de defensa debe evitar adquirir la toxoplasmosis durante la gestación que cursa; para ello se abstendrá de entrar en contacto con gatos o con cualquier animal doméstico mamífero o ave, o con tierra infectada $o$ expuesta a los excrementos del gato; usará guantes para trajinar con carne cruda o con tierra que pueda estar infectada; en el caso de no haber usado guantes, debe practicar de inmediato lavado de las manos con jabón y agua más cepillado de las uñas. No llevar a la boca las manos que hayan estado en contacto con tierra, por ejemplo al efectuar la horticultura. No consumir carne cruda ni semicruda como quipe, hamburguesas, carne a la parrilla semi cruda.

Si hay gato en la casa se le debe enseñar a defecar en un cajón con tierra,

\section{BIBLIOGRAFIA}

1. AMBROISE-THOMAS, P., ROUGIER, D., GROS, A. Y CAGNARD, M. Pruebas cutáneas con nuevos antígenos para chequear la inmunidad al toxoplasma. En: Simposio Interamericano de Toxoplasmosis. Editora Guadalupe Ltda., Bogotá. 189, 1984.

2. ARAUJO, F.G. Avances recientes en el diagnóstico e inmunologıa de la Toxo plasmosis. En: Simposio Interamericano de Toxoplasmosis. Editora Guadalupe Ltda. Bogotá, 119, 1984.

3. BARRERO, A. DE. Anticuerpos antitoxoplasma en humor vítreo: En: Simposio el que se debe cambiar a diario, eliminando las heces por cremación; alimentar el gato con enlatados o en su defecto, con carne bien cocida (48).

Para que la mujer adquiera defensas desde niña, es prudente obsequiarle un gatico en su niñez.

\section{RESUMEN}

Se hace un recuento de la epidemiología, del diagnóstico, de la evolución y de la profilaxis de la toxoplasmosis. Para que la toxoplasmosis sea congénita es indispensable que la infección sea adquirida durante el embarazo que cursa. Se estudia la formación de anticuerpos en la madre y en el feto.

Se analizan los criterios que deben primar para el inicio del tratamiento en la mujer embarazada.
Interamericano de Toxoplasmosis. Editora Guadalupe Ltda. Bogotá, 217, 1984.

4. BEAUVAIS, B. La toxoplasmosis adquirida. La Presse Médicale. 8: 1081986.

5. BONFANTE, G.R., ALVAREZ, N.M., DE., ANZOLA, N.H. DE., CRESPO, L.R. DE, BONFANTE, C.R. y PENALLOZA, S.C. DE. Toxoplasmosis en 14 Estados de Venezuela. Bol. de Oficina Sanit. Panamericana. 96: 502, 1984.

6. BOTERO, D. y cols. Estudio sobre la toxoplasmosis humana en Colombia Antioquia Médica. 15: 325, 1965

7. BOTERO, U.J., JUBIZ, H.A Y HENAO, G. Toxoplasmosis. En: Obstetricia $y$ 
Ginecología. 3a. ed. Carvajal, S.A Ed, $297,1985$.

8. CALANDRA, D., ANDERSEN OA. REYNOSO, R.M., COMPARATO, M.R. y cols. Toxoplasmosis. En: Ecología embrionaria y fetal. Ed. Panamericana Buenos Aires, 158, 1975.

9. CAMARGO, M.E., ALBUQUERQUE., E.M.D. DE, y ACOSTA, V.F.A. Diagnostico serológico de la toxoplasmosis en recién nacidos con enfermedad congénita aparente. En: Simposio Interamericano de Toxoplasmosis. Editora Guadalupe Ltda, Bogotá. 139, 1984.

10. CAMARGO, M.E. Pruebas inmunoenzimáticas en el diagnóstico de la Toxoplasmosis. En: Simposio Interamericano de Toxoplasmosis. Editora Guadalupe, Ltda. Bogotá, 175, 1984.

11. CORREDOR, A.A. Toxoplasmosis en Colombia. En: Simposio Interamericano de Toxoplasmosis. Editora Guadalupe Ltda, Bogotá, 64. 1984.

12. DESMONTS, G. y COUVREUR J. Congenital toxoplasmosis: a prospective study of 378 pregnancies. N. Engl. J. Med. 290: 1110, 1974.

13. DESMONTS, G. Toxoplasmose acquise de la femme encéinte. Lyon Médical 248: 115,1982 .

14. DUARTE-CONTRERAS, A. BUSTAMANTE, A.G., LUZARDO, M.L.F. Y PALAU, C.M.J. Toxoplasmosis y embarazo. Rev. Colomb. Obstet. Ginecol. 21: 95, 1970.

15. DUARTE-CONTRERAS, A. Y DUARTE, B.C.I. Criterios para el diagnóstico y el tratamiento de la Toxoplasmosis
Rev. Colomb. Obstet. Ginecol. 35: 205 1984.

16. DUFLO, B. Diagnóstico serológico de Toxoplasmosis. En: Kamaun J.P. Guía de exámenes de Laboratorio. Ed. Frajeville. 136, 1981.

17. FRENKEL, J.K. y RUIZ, A. Toxoplasmosis humana. Una revisión. Acta Medica Costarric. 16: 5, 1973.

18. FRENKEL, J.K. El tratamiento de la toxoplasmosis. En: Simposio Interamericano de Toxoplasmosis. Editora Guadalupe Ltda. Bogotá, 95. 1984

19. FUNDENBERG, H.H. y cols. Toxoplasmosis. En: Inmunología Clınica. Ed. El Manual Moderno. México 694, 1982.

20. GUARDIOLA, C.F. DE, y CERON, E.M.C. Prevalencia de infestacion por Toxoplasma Gondii en un grupo de madres y sus productos de gestación Rev. Colomb. Obste. Ginecol. 34: 178, ?983.

21. HENAO, O. Toxoplasmosis y embarazo. Manual de Normas Gíneco Obstétricas. Hospital San Ignacio. Universidad Javeriana. 143, 1986.

22. HUNTER, K. y cols. Prenatal screening of prenatal women for infections caused by citomegalovirus, Epstein-Barr virus, herpes virus, rubeola and toxoplasma Gondii. Am. J. Obstet. Gynecol. 145: 269, 1983.

23. JACOBS, Z., REMINGTON, J. Y MELTON, M. The resistence of the encysted form of toxoplasma Gondii. J. Parasitol. 46: $11,160$.

24. KAGAN, I.G. Diagnóstico serológico de toxoplasmosis. En: Simposio Interameri- 
cano de Toxoplasmosis. Editora Guadalupe Ltda. Bogotá, 112, 1984.

25. KEAN, B.H. Clinical toxoplasmosis 50 years. Trans. Roy. Soc. Trop. Med. Hyg. 66: 549, 1972.

26. KNIERIM y cols. Practical aspects in the inmuno diagnosis of toxoplasmosis Bol. Chil. Parasitol. 35: 3, 1980.

27. LANGMAN, J. Toxoplasmosis. En: Embriología médica. Ed. Panamericana, Buenos Aires. 4a. ed. 110, 1982.

28. MAEKELT, G.H. La toxoplasmosis en Venezuela. Simposio Interamericano de Toxoplasmosis. Editora Guadalupe Ltda. Bogotá, 52, 1984.

29. MAEKELT, G.H. La reaccion de hemo aglutinación indirecta aplicada al diagnóstico de la toxoplasmosis. En: Simpo. sio Interamericano de Toxoplasmosis Editora Guadalupe Ltda. Bogotá, 160, 1984.

30. MATSUBAYASHI, H. Y AKAO S. Morphogenical studies on the development of the toxoplasma cyst Am. J. Trop. Med. 12: 321, 1963.

31. MEHLORM, H. Ciclo de Vida de Sarcosporidia. En: Simposio Interamericano de Toxoplasmosis. Editora Guadalupe Ltda. Bogotá, 31, 1984.

32. montoya, M. y cols. Prevalencia de anticuerpos para toxoplasma Gondii en bovinos y porcinos. Bol. of San. Pan., $91 ; 219,1981$.

33. MONTOYA, M.F. Toxoplasmosis animal y en manipuladores de carne en Colombia. En: Simposio Interamericano de
Toxoplasmosis, Editora Guadalupe Ltda. Bogotá, 247, 1984.

34. MOZZICONACCI, P. y cols. Enfermedades infecciosas del niño. Ed. Jins, Barcelona. 1973.

35. NAOT, Y. y cols. Duration of IgG antibodies to toxoplasma Gondii after acute acquired toxoplasmosis. Inrect, Dis. 145: 770, 1982.

36. NELSON, M.M. Mammalian fetal development and antimetabolites. En: Antimetabolites and Cancer. Washington, D.C. American Assoc. for the advancement of Science. 1955.

37. REMINGTON, J.S., MILLER, M.J. and BROWNLEE, I. IgG antibodies in acute toxoplasmosis: prevalence and sigrifíicance in acquired cases. J. Lab. Clin. Med. 71: 855, 1968.

38. REMINGTON, J.S. y cols. Studies on Toxoplasmosis in Salvador. Trnas. Roy. Soc. Trop. Med. Hyg. 64: 252, 1970.

39. REMINGTON, J.S. y DESMONTS, G. Infections diseases of the fetus and newborn infant. J.S. Remington y J. Klein, eds. Saunders Co. 2nd. ed. Philadelphia. 1983.

40. RESTREPO, M. Reacción de Sabin Feldman. En: Simposio Interamericano de Toxoplasmosis. Editora Guadalupe Ltda. Bogotá, 155, 1984.

41. ROLLINS, D.F. y cols. Detection of toxoplasmal antigen and antibody in ocular toxoplasmosis. Arch. Ophtalmol. 101: 455, 1983.

42. RYNING, F.W., MCLEOD, R., MADDOY, J.C., HIRUT, S. Y REMINGTON, J.S. Ann. Intern. Med. 90: 47 
43. SIEGEL, J., LUNDE, M.N. y GELDERMAN. A.H. Blodd. 34: 388, 1971.

44. WALLACE, G.D. The role of cat in the natural history of toxoplasma Gondii. Am. J. Trop. Med. Hyg. 22: 313, 1973.

45. WIESNER, J. Toxoplasmosis y gestación. Rev. Colomb. Obstet. Ginecol. 34: 127, 1983.

46. WEISER, R.S., MYRVIK, Q.N. Y PEARSALL, N.N. Inmunología. Ed. Interamericana, S.A. México. 1980
47. WERNER, APT.B. Epidemiología de la Toxoplasmosis. Simposio Interamericano de Toxoplasmosis. Editora Guadalupe Ltda. Bogotá, 37, 1984.

48. WERNER, APT, B. Clínica de la toxoplasmosis adquirida. En: Simposio Interamericano de Toxoplasmosis. Editora Guadalupe Ltda. Bogotá, 275, 1984. 